\title{
Structural characterization of hemoglobins from Monilifera and Frenulata tubeworms (Siboglinids): First discovery of giant hexagonal-bilayer hemoglobin in the former "Pogonophora" group
}

\author{
Cédric Meunier ${ }^{\mathrm{a}, 1}$, Ann C. Andersen ${ }^{\mathrm{a}, *}$, Matthieu Bruneaux ${ }^{\mathrm{a}}$, Dominique Le Guen ${ }^{\mathrm{b}}$, Peran Terrier $^{\mathrm{c}}$, \\ Emmanuelle Leize-Wagner ${ }^{c}$, Franck Zal ${ }^{\text {b,2 }}$ \\ a UPMC Université Paris VI, UMR 7144, Equipe Ecophysiologie des Invertébrés Marins des Milieux Extrêmes, Station Biologique de Roscoff, Place Georges Teissier, \\ B.P 74. F-29682 Roscoff-cedex, France \\ ${ }^{\mathrm{b}}$ CNRS, UMR 7144, Equipe Ecophysiologie des Invertébrés Marins des Milieux Extrêmes, Station Biologique de Roscoff, Place Georges Teissier, B.P 74. F-29682 Roscoff-cedex, France \\ ${ }^{c}$ Laboratoire de Dynamique et Structure Moléculaire par Spectrométrie de Masse, UMR 7177, CNRS-ULP, Institut de Chimie LC3, ISIS, F-67083 Strasbourg, France
}

\section{A R T I C L E I N F O}

\section{Article history:}

Received 19 August 2009

Received in revised form 11 September 2009

Accepted 12 September 2009

Available online 19 September 2009

\section{Keywords:}

Annelida

Cold-seeps

Extracellular hemoglobins

Haakon Mosby Mud volcano

Mass-Spectrometry

Multi-angle-laser-light-scattering

Phylogeny

Storegga-slide

\begin{abstract}
A B S T R A C T
Siboglinids are symbiotic polychete annelids having hemoglobins as essential oxygen- and sulfide-carriers for their endosymbiotic bacteria. We analyzed the structure of the hemoglobins from two species of siboglinids: the monilifera Sclerolinum contortum and the frenulata Oligobrachia webbi (i.e. haakonmosbiensis) from Norwegian cold seeps. Measured by Multi-Angle Laser Light Scattering (MALLS), Sclerolinum shows a $3190 \pm 50 \mathrm{kDa}$ hexagonal bilayer hemoglobin (HBL-Hb) and a $461 \pm 46 \mathrm{kDa}$ ring-Hb, just as vestimentifera, whereas Oligobrachia has a $409 \pm 3.7 \mathrm{kDa}$ ring-Hb only. Electrospray Ionization-Mass Spectrometry (ESI-MS) showed Sclerolinum HBL-Hb composed of seven monomeric globins (15-16 kDa), three disulfide-bonded globin heterodimers and three linkers. The heterodimers always contain globin-b (15814.4 $\pm 1.5 \mathrm{Da})$. Sclerolinum ring- $\mathrm{Hb}$ is composed of globins and dimers with identical masses as its HBL-Hb, but lacks linkers. Oligobrachia ring-Hb has three globin monomers (14-15 kDa) only, with no disulfide-bonded dimers. Comparison of Sclerolinum hemoglobins between Storegga and Haakon Mosby Mud Volcano, using the normalized height of deconvoluted ESI-MS peaks, shows differences in globin monomers abundances that could reflect genetic differences or differential gene expression between distinct seep populations. The discovery of HBL-Hb in Sclerolinum is a new element supporting the hypothesis of monilifera being phylogenetically more closely related to vestimentifera, than to frenulata.
\end{abstract}

(C) 2009 Elsevier Inc. All rights reserved.

\section{Introduction}

Siboglinids are tube dwelling marine annelids having neither gut nor mouth, but relying on internal chemoautotrophic bacteria for their nutrition. They comprise in fact four symbiotic tubeworm clades: (1) the big vestimentifera found at hydrothermal vents or cold-seeps,

Abbreviations: ESI-MS, Electrospray Ionization-Mass Spectrometry; Hb, hemoglobin; HBL-Hb, Hexagonal Bi-Layer Hemoglobin; HMMV, Haakon Mosby Mud Volcano; ring-Hb, ring-shaped hemoglobin of about $400 \mathrm{kDa}$.

* Corresponding author. Tel.: +33 2982923 38; fax: +33298292324.

E-mail addresses: Cedric.Meunier@awi.de (C. Meunier), andersen@sb-roscoff.fr (A.C. Andersen), bruneaux@sb-roscoff.fr (M. Bruneaux), leguen@sb-roscoff.fr (D. Le Guen), peranter@yahoo.com (P. Terrier), leize@chimie.u-strasbg.fr (E. Leize-Wagner), franck.zal@hemarina.com (F. Zal).

${ }^{1}$ Present address: Biologische Anstalt Helgoland Marine Station, Alfred Wegener Institute for Polar Marine Research, Ostkaje 1118, 27498 Helgoland, Germany.

2 Present address: HEMARINA SA, Aéropôle Centre, Biotechnopôle, F-29600 Morlaix, France.
(2) the thread-like frenulata buried in seeps, mud volcanoes or in anoxic firth sediments, (3) the thread-like monilifera in rotten wood, mud volcanoes or hydrothermal vents, and (4) the more recently discovered small Osedax spp. in decaying whale or cow bones (Rouse et al., 2004; Braby et al., 2007). Both morphological data (bodysegmentation, chetae and larval type) and molecular cladistics indicate that all siboglinids are polychete annelids, see for review (Rouse 2001; Halanych 2005). Frenulata and monilifera were formerly grouped together (Ivanov 1963; Ivanov 1991) under the name pogonophora meaning "beard worm" in Greek, due to their hair-like gill tentacles. However, the monilifera lack the anterior bridle (i.e. frenulum) characteristic of frenulata. This and several other morphological characteristics (see (Southward 2000) for review) led to distinguish monilifera from frenulata. Furthermore, based on $18 \mathrm{~S}$ nuclear rDNA gene and 16S mitochondrial rDNA gene (Halanych 2001) showed monilifera as a sister group to vestimentifera. In this paper we will use the name "pogonophora" in a more practical than systematical sense, to indicate the thread-like siboglinids that include both frenulata and monilifera. 
With a single methanotrophic exception in Siboglinum poseidoni from Skagerrak (Schmaljohann and Flugel, 1987), the symbiotic bacteria housed in the siboglinids are all sulfur-oxidizing, as in the two species found at the Norwegian margin: Sclerolinum contortum and Oligobrachia webbi (haakonmosbiensis) (Lösekann et al., 2008). Although molecular sequences from symbionts of 0 . webbi (haakonmosbiensis) did cluster with those of $O$. mashikoi symbionts, in a clade unaffiliated with any known methane- or sulfur-oxidizing bacteria, the molecular data suggest that both Norwegian siboglinid species harbor chemoautotrophic sulfur-oxidizing symbionts (Lösekann et al., 2008). To feed the siboglinids need to intake oxygen, sulfide and carbon dioxide from the surrounding environment, and to bring these elements to their endosymbionts stored in the trophosome, a soft specialized tissue located in their posterior body-part. From these elements, the bacteria synthesize organic compounds that are transferred to the host, either by exocytosis in the blood or by intracellular digestion of the bacteria. Oxygen and sulfide are both transported by the hemoglobins. These proteins are freely dissolved in their blood or in the coelomic fluid surrounding the blood vessels. The hemoglobins in Siboglinids are thus essential not only to breathe, but also to fuel their endosymbionts and to cope with the toxic elements from their environment. The structures of these hemoglobin molecules are dealt with in this study.

The hemoglobin has been extensively studied in Riftia pachyptila (Jones 1981) the giant tubeworm first discovered around the East Pacific hydrothermal vents. Riftia harbors three extracellular hemoglobins: two dissolved in its blood and one in its coelomic fluid (Arp et al., 1990; Zal et al., 1996a). The largest vascular hemoglobin is a molecule of $3500 \mathrm{kDa}$ visible in electron microscopy as two stacked hexagons of $24.5 \mathrm{~nm}$ diameter by $16 \mathrm{~nm}$ height (Terwilliger 1980; Zal et al., 1996b). This type of hemoglobin is common in many annelids (Green et al., 2001) and was first called "erythrocruorin" according to its red color. The commonly admitted "bracelet model" consists of a hexagonal-bilayer hemoglobin (abbreviated HBL-Hb) made of 144 functional globin chains and 36 structural linker chains (Zal et al., 1996b). However, whereas most annelids have the extracellular HBL-Hb only, Riftia has two other extracellular hemoglobins: a second vascular hemoglobin and also a coelomic hemoglobin, both having a molecular weight of $400 \mathrm{kDa}$, although they differ in their subunit composition and are consequently different molecules (Zal et al., 1996b). The $400 \mathrm{kDa} \mathrm{Hb}$ are molecules measuring about one third the diameter of the HBL-Hb, looking like small circular rings on TEM microphotographs, and will therefore be named ring-Hb in the present study. In Riftia, all three hemoglobins are able to bind oxygen and sulfides, but none to such large amounts as the HBL-Hb (Zal et al., 1997) with 144 oxygen binding sites per protein. HBL-Hb binds both oxygen and sulfide reversibly, but at distinct sites of the molecule, avoiding both poisoning of the worm from free sulfides and spontaneous reaction between the two molecules (Arp et al., 1987; Zal et al., 1998).

In other vestimentifera species, such as Lamellibrachia barhami and Escarpia spicata which live in cold-seep areas of the East-Pacific ocean, both types of hemoglobins have also been discovered (Terwilliger et al., 1985). In Lamellibrachia from the seeps off Sagami bay in Japan, the HBL-Hb is about $3000 \mathrm{kDa}$, with four different hemecontaining-chains i.e. globin chains (Suzuki et al., 1993) (A1-AIV) and two different linker chains (AV and AVI) for the assembly of the globin chains (Suzuki et al., 1988). The second $\mathrm{Hb}$ is a ring-Hb about $440 \mathrm{kDa}$ built of only four globin chains (Suzuki et al., 1993). The primary sequence of the N-terminal part of the ring- $\mathrm{Hb}$ shows 76 to $85 \%$ homology between various Lamellibrachia species suggesting they are closely related (Suzuki et al., 1993).

Frenulata tubeworms' small size makes blood analyses difficult, although it has been known for a long time that they contain hemoglobin (Southward and Southward, 1963). Terwilliger and colleagues (Terwilliger et al., 1987) examined the hemoglobin in live specimens of six frenulata species. All six species had a hemoglobin of about $350-400 \mathrm{kDa}$, as shown by size exclusion chromatography and gel electrophoresis (Terwilliger et al., 1987). This led Terwilliger and colleagues to conclude that pogonophora (at least the frenulata pogonophora) lack annelid HBL-Hb, but only harbor the ring-Hb that they share with the vestimentifera. Thus, the presence of the ring-Hb would be a synapomorphy of siboglinids. The ring- $\mathrm{Hb}$ of the frenulata Oligobrachia mashikoi that lives buried in the sediment from Tsukumo Bay in Japan has been studied extensively. Its globin chains share 35-52\% identity with HBL-Hb from Lumbricus, Tylorhynchus and Lamellibrachia suggesting a close relationship between annelida, pogonophora and vestimentifera (Yuasa et al., 1996). Nagakawa and colleagues (Nakagawa et al., 2005) sequenced the full length of four kinds of globin chains (A1, A2, B1 and B2) from Oligobrachia mashikoi. The structure of its molecule has been crystallized, and shows the ring-Hb as being hollow-spherical, and composed of a total of 24 globins associated as a dimer of dodecamers (Numoto et al., 2005; Numoto et al., 2006; Numoto et al., 2008).

The present work investigates the structure of the hemoglobins from two pogonophora species from the deep-sea cold seeps off Norway, aiming to compare their structural characteristics with those of other annelids, and to discuss the molecular and phylogenetic implications.

\section{Materials and methods}

\subsection{Animal sampling}

Specimens of the monilifera Sclerolinum contortum and of the frenulata Oligobrachia haakonmosbiensis i.e. webbi Brattegard, 1966 (Brattegard 1966), (I. Smirnov and S. Galkin personal communication, July 2007) were collected during the oceanographic cruise "VICKING" (May and June 2006) from the flanks of Haakon Mosby Mud Volcano (HMMV), located on the northwestern coast of Norway $\left(72^{\circ} \mathrm{N}-\right.$ $14.5^{\circ} \mathrm{E}$ ) at $1200 \mathrm{~m}$ depth. Specimens belonging to the two same species were sampled at the discrete cold seep sites of Storegga flange $\left(65^{\circ} \mathrm{N}-4.5^{\circ} \mathrm{E}\right)$, at $750 \mathrm{~m}$ depths. At each site, the submersible "VICTOR 6000 " from the French research vessel "Pourquoi-pas?" dug the tubeworms from the sediment using blade cores. Upon recovery, the tubeworms were extracted from the mud by flushing seawater through a $1 \mathrm{~mm}$ sieve. The tubes measured about $250 \mu \mathrm{m}$ and $500 \mu \mathrm{m}$ in diameter, for Sclerolinum and Oligobrachia respectively. The recovered tube lengths for both species were from one to several decimeters, and sometimes exceeded $70 \mathrm{~cm}$. Sclerolinum in particular could be much longer as it has a particularly twisted tube. The worms were taken from their tubes in ice-cold seawater, under an Olympus SZ9X stereo zoom binocular microscope. They were then pooled ten by ten in $0.5 \mathrm{ml}$ centrifugal tubes stored on ice, and rapidly frozen in liquid nitrogen for transportation to the laboratory, where they were kept frozen at $-80^{\circ} \mathrm{C}$. Other specimens still in their tubes were frozen directly ten by ten. We had 9 samples of ten individuals each for this study, distributed as three Oligobrachia samples: two from HMMV, and one from Storegga; six Sclerolinum samples: two from HMMV and four from Storegga, resulting in an analysis of 30 Oligobrachia and 60 Sclerolinum individuals.

\subsection{Hemoglobins purification by size-exclusion chromatography (SEC)}

Each aliquot of 10 naked tubeworms were ground in $300 \mu \mathrm{L}$ icecold saline buffer reproducing the composition of the physiological fluids in the siboglinids $\left(400 \mathrm{mM} \mathrm{NaCl}, 3 \mathrm{mM} \mathrm{KCl}, 32 \mathrm{mM} \mathrm{MgSO}_{4}\right.$, $11 \mathrm{mM} \mathrm{CaCl}_{2}, 50 \mathrm{mM}$ bis-tris-propane, $\mathrm{pH}$ 7.0). The homogenate was centrifuged at $14000 \mathrm{~g}$ at $4{ }^{\circ} \mathrm{C}$ for $10 \mathrm{~min}$. The same protocol was used for tubeworms within their tubes. The proteins in the supernatant were separated by analytical size-exclusion chromatography performed on a high-resolution Superose 6 10/300 Tricorn (GL) column 
(GE Healthcare), with a fractionation range of 5 to $5000 \mathrm{kDa}$. Elution rate was $0.5 \mathrm{~mL} / \mathrm{min}$ in saline buffer; the absorbance of the eluate was monitored at $280 \mathrm{~nm}$ and $414 \mathrm{~nm}$, to measure protein and heme concentration, respectively. The heme-containing protein were collected separately and concentrated on micro-centrifugal filter devices Centricon-10 (Millipore). Purity of the collected fractions was assessed with the same method. When required, one or two additional purification steps were performed using the same protocol to obtain purely isolated heme-containing protein fractions.

\subsection{Hemoglobin molecular mass determination by Multi-angle laser-light scattering (MALLS )}

To identify each purified heme-containing protein fraction, we determined their precise molecular mass by MALLS measurements using a DAWN EOS multi-angle detector system (Wyatt Technology Corp., USA) and a refractive index detector (Waters 2487), directly coupled to the SEC system described above. We obtained the precise molecular mass of each heme-containing protein by the software Astra 4.90.08 (Wyatt Technology Corp., USA) using the Debye fit method, with a dn/dc value set to $0.190 \mathrm{ml} / \mathrm{g}$, typical of non-glycosylated proteins.

\subsection{Hemoglobin observation by Transmission Electron Microscopy (TEM)}

The molecular shapes of the hemoglobins were observed by TEM, both on native blood and after purification of the hemoglobins. Blood drops, squeezed from the gill-tentacles of live specimens on board and diluted in saline buffer, were laid on carbon-film coated grids, and negatively stained in uranyl acetate $(0.5 \%)$ according to (Valentine et al., 1968). The same technique was performed for purified hemoglobin fractions. The grids were observed with a JEOL SX 1200 electron microscope, and photomicrographs were taken at $\times 50000$ and $\times 100000$ magnifications. The sizes of the $\mathrm{Hb}$ molecules were directly measured on the microphotographs.

\subsection{Quaternary Hemoglobin structure by Electrospray Ionization Mass Spectrometry (ESI-MS)}

An ESI-MS analysis was performed on each purified hemoglobin type from each tubeworm species and from each collection site. Purified hemoglobin samples were extensively desalted in de-ionized water by successive concentration-dilution cycles using $10 \mathrm{kDa}$ Microcon centrifugal filter devices (Millipore) and then lyophilized. ESI-MS analyses were performed in denaturing conditions. Each sample was dissolved at a final concentration of proteins about $0.5 \mathrm{mg} / \mathrm{ml}$ in a water/ acetonitrile/formic acid mix (50:50:0.2 volume). Analyses were performed on a microTOF instrument (Bruker Daltonics, Bremen, Germany) and acquisition was performed over the 600-3000 m/z range. The nebulization gas pressure was 0.3 bar, drying gas flow was $3 \mathrm{Lmin}^{-1}$, the capillary exit voltage was set to $160 \mathrm{~V}$. Calibration was performed using myoglobin (Sigma-Aldrich). Mass spectra were deconvoluted using maximum entropy deconvolution (Bruker Data Analysis v3.2 software). Assuming that the globin chains have similar behavior during ionization process (see Results Section 3.3), abundances were estimated by normalizing each peak height by the height of the most intense peak. Since analyses were performed on pools of 10 individuals, the compared masses and abundances can reasonably be taken into account to hypothesize differences between samples.

\section{Results}

\subsection{SEC-purified Hemoglobins characterized by MALLS}

The analysis by size-exclusion chromatography of Sclerolinum samples resulted in the elution of four peaks of heme-containing proteins, whereas Oligobrachia samples produced only three (Fig. 1A, B). We analyzed then each purified peak separately, using both MALLS and TEM to identify each fraction by its molecular mass and quaternary structure. The peaks (II) were clearly the most abundant hemoglobin fraction in each species. In Sclerolinum the area of peak (III) was about half the area of peak (II), meaning that component (III) is about half as abundant as the major component (II). SEC, MALLS and TEM results were similar for both sampling sites: Storegga and HMMV.

In Sclerolinum, MALLS estimated the mass of the major fraction (II) to $3190 \pm 50 \mathrm{kDa}$ ( $n=97$ slices), corresponding to the typical mass of an HBL-Hb (Fig. 2A), whereas fraction (III) had a molecular mass of about $461 \pm 46 \mathrm{kDa}$ ( $n=97$ slices) corresponding to the expected $400 \mathrm{kDa}$ mass of a ring-Hb. Their quaternary structures observed by TEM confirmed the hexagonal bilayer structure and the ring structure respectively, and are shown below (Section 3.2 and Fig. 3). Oligobrachia major fraction (II) had a mass of $409 \pm 3.7 \mathrm{kDa}$ ( $n=97$ slices) corresponding to a ring-Hb structure (Figs. 2B, 3).

On the contrary, the minor peaks I analyzed by MALLS showed that the average molecular mass of the molecules in the first eluted fraction (I) in Sclerolinum and Oligobrachia were variable and always greater than $10 \mathrm{MDa}$. Observed under TEM the corresponding proteins of each fraction (I) resemble large white flakes more or less clustered together (data not shown). Their very high masses and their lack of homogeneous structure allowed us to conclude that these fractions (I) corresponded to various aggregates containing hemoglobin macromolecules in each species. Finally, the minor peak (IV) in Sclerolinum showed a mass of $63.8 \pm 2 \mathrm{kDa}(n=241$ slices), which corresponds to globin tetramers, issued from hemoglobin multimeres dissociation. The very small last peak (III) of Oligobrachia eluted even later than the globin tetramers for Sclerolinum, and is thus likely to be smaller degradation products appearing during the purification steps of the hemoglobin.

\subsection{Transmission electron microscopy}

The comparison of native and purified hemoglobin molecules is shown in Fig. 3. Sclerolinum contained both hexagonal-bilayer
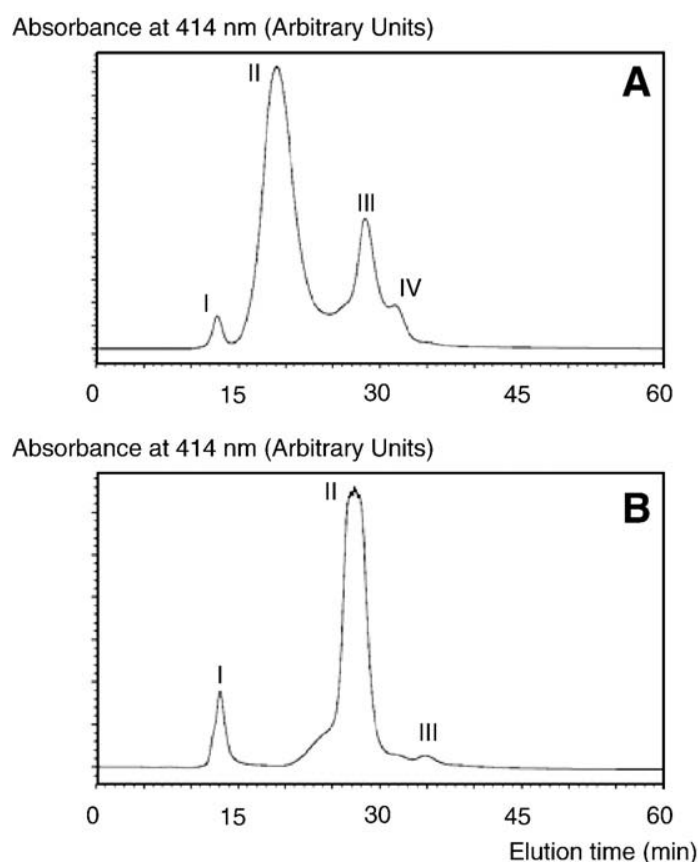

Fig. 1. Compared SEC profiles on whole tubeworm extracts. A - The purified total extracts of Sclerolinum showed four peaks of heme-containing proteins, from which the second peak was the major fraction (II). B - The chromatogram of Oligobrachia showed only three peaks, with the second being the major fraction (II) that had almost the same elution time as fraction (III) of Sclerolinum, indicating their very close molecular masses. 

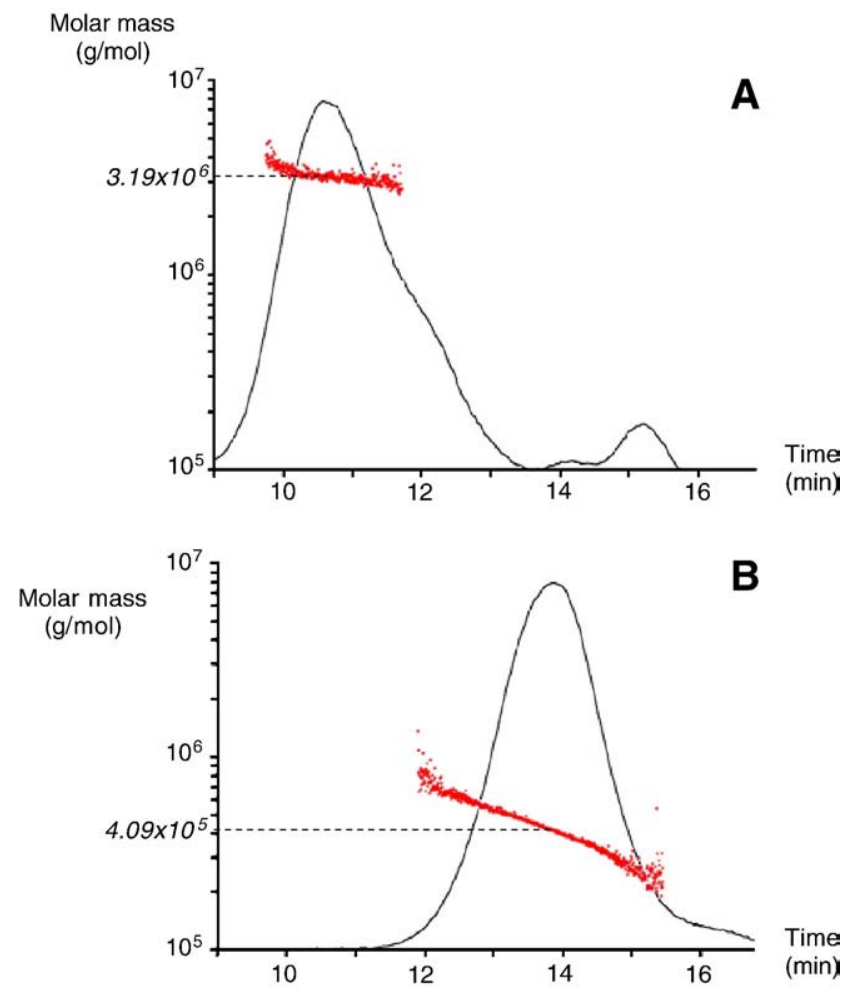

Fig. 2. Molecular masses of the major Hemoglobin fractions measured by MALLS A - Measure of the molecular mass of the molecules in the purified fraction (II) of Sclerolinum showing a value of 3.19 MDa, which corresponds to a typical mass of HBL-Hb. B - Measure of the molecular mass of the purified fraction (II) of Oligobrachia showing a value of $409 \mathrm{kDa}$.

structures (HBL-Hb) and the small ring-shaped molecules (ring- $\mathrm{Hb}$ ) in its blood (Fig. 3A). Purification of the major fraction (II) from Sclerolinum led to the isolation of the HBL-Hb (Fig. 3B), whereas the fraction (III) corresponded to the small ring-shaped molecules (Fig. 3D). Oligobrachia native blood/coelomic fluid contained only the small ring-shaped molecules (Fig. 3C) that looked very similar to those of Sclerolinum after purification (Fig. 3D). The blood of the vestimentiferan tubeworm Riftia pachyptila contains both HBL-Hb and small ring-shaped molecules (Fig. 3E), whereas the blood of the intertidal lugworm Arenicola marina contains HBL-Hb only (Fig. 3F). Size measurements of Sclerolinum HBL-Hb on TEM photomicrographs gave a diameter of $22.8 \mathrm{~nm} \pm 2.9 \mathrm{~nm}(n=31)$, and a thickness of $16.4 \mathrm{~nm} \pm 1.2 \mathrm{~nm}(n=26)$.

\subsection{Electrospray Ionization Mass Spectrometry (ESI-MS) analyses}

The precise masses of the different hemoglobins constituents were obtained by ESI-MS (Fig. 4). The table is an overview of the composition and subunit masses of the hemoglobins for the two species from both sites taken together.

Sclerolinum exhibited a broad range of molecular masses with seven different monomeric chains in the HBL-Hb, six of which are also present in the ring- $\mathrm{Hb}$ (Table 1 ). The monomer masses range from 15693 to $16592 \mathrm{Da}$, which is consistent with the expected mass for globin chains. Three covalently bound dimers were also present in both HBL-Hb and ring-Hb. They were made of the globin b-chain associated to one of three different globin chains. All dimer constituents were present as monomers, except for the ring- $\mathrm{Hb}$ in which the b-chain was only observed in heterodimers. Finally three different linker chains were observed in the HBL-Hb. Although the ring-Hb of Sclerolinum is composed of the same globins and dimers as its HBL-Hb, the hypotheses that its ring-Hb could be an artifact, i.e. a degradation product of its HBL-Hb during storage or purification of the sample, can be ruled out because of the presence of ring- $\mathrm{Hb}$ in freshly collected blood, as observed under TEM (Fig. 3A). In addition, the profiles obtained for SEC purification corresponds to those seen for Riftia blood after storage of the sample, and showing a higher amount of $\mathrm{HBL}-\mathrm{Hb}$ than of ring-Hb, whereas the degradation products are very minor fractions (Zal et al., 1996a).

Oligobrachia ring-Hb had three different globin monomers only. No covalent dimer was observed. Linker chains enabling the association into a hexagonal bilayer were not present.

To go into finer structural details we compared the relative abundances of each monomeric globin chains in Sclerolinum hemoglobins according to its collection site, using the normalized height of deconvoluted ESI-MS peaks (Fig. 5). Abundance data must generally be considered with care since a discrepancy between the ESI-MS estimated values and the real ones could exist, due to different behaviors of the subunits during the ionization process. However we compare the abundance of each kind of globin chain from the hemoglobins of Sclerolinum from one site with the same globin chain (i.e. of identical mass) from the other site, and thus these chains should behave identically during ionization. When comparing globin chains of different masses within a sample, we assume that very closely related globin molecules are likely to behave similarly during the ionization process. The compared monomeric globin abundances in Sclerolinum look quite similar between the two hemoglobin types at each collection site: in particular chain-a is the most abundant globin chain in both HBL-Hb from each site. However some differences do exist: chain-b that is always present in HBL-Hb was not observed in the ring- $\mathrm{Hb}$ from either sites, chain-e was not present in the ring-Hb from Storegga monilifera, and no chain-f was observed in neither ring-Hb nor HBL-Hb from Haakon Mosby Mud Volcano monilifera.

\section{Discussion}

\subsection{HBL-Hb present in monilifera and phylogenetic implications}

The analyses of the hemoglobins in the two species of "pogonophora" siboglinids from the Norwegian cold seeps show that the monilifera Sclerolinum contortum has two types of extracellular hemoglobin: an HBL-Hb and a ring-Hb, just as the vestimentifera, whereas the frenulata Oligobrachia webbi has a ring-Hb only, as the remaining species of frenulata investigated so far (Terwilliger et al., 1987; Numoto et al., 2005). It is the first time that an HBL-Hb is described in a "pogonophora" or non-vestimentiferan siboglinid. Monilifera comprise a single genus: Sclerolinum, with to date seven nominal species. As these worms are tiny (less than $0.5 \mathrm{~mm}$ in diameter) and often live in environments that are not easily accessible, few of them have been investigated so far for molecular studies. Our study adds a new Sclerolinum species to the list of molecular investigations. The discovery of HBL-Hb in Sclerolinum as in vestimentifera is interesting in an evolutionary point of view, as it corroborates morphological cladistic analysis (Rouse 2001) and several molecular studies (Halanych 2005) showing that among siboglinids, monilifera are more closely related to vestimentifera than to frenulata (Fig. 6). It would be interesting to check what type of hemoglobin is present in the other frenulata genera that have not been investigated so far, as also in the bone siboglinid Osedax, to further assess the evolutionary relationships within siboglinids.

It is known that the extracellular hemoglobins have selfassembling properties. HBL-Hb and ring- $\mathrm{Hb}$ are built of the same type of elemental globins (sometimes even the same globins, in the case of Sclerolinum) associated in various multimeric forms. The only structural difference between ring-Hb and HBL-Hb is the presence of linkers to build the two-tiered hexagonal shape of the HBL-Hb. This huge molecule (or the related green hexagonal bilayer chlorocruorin $\mathrm{Chl}-\mathrm{Hb}$ ) is present in about 15 annelid families, from quite diverse clades: both tube-dwelling and active burrowers, including clitellata. 

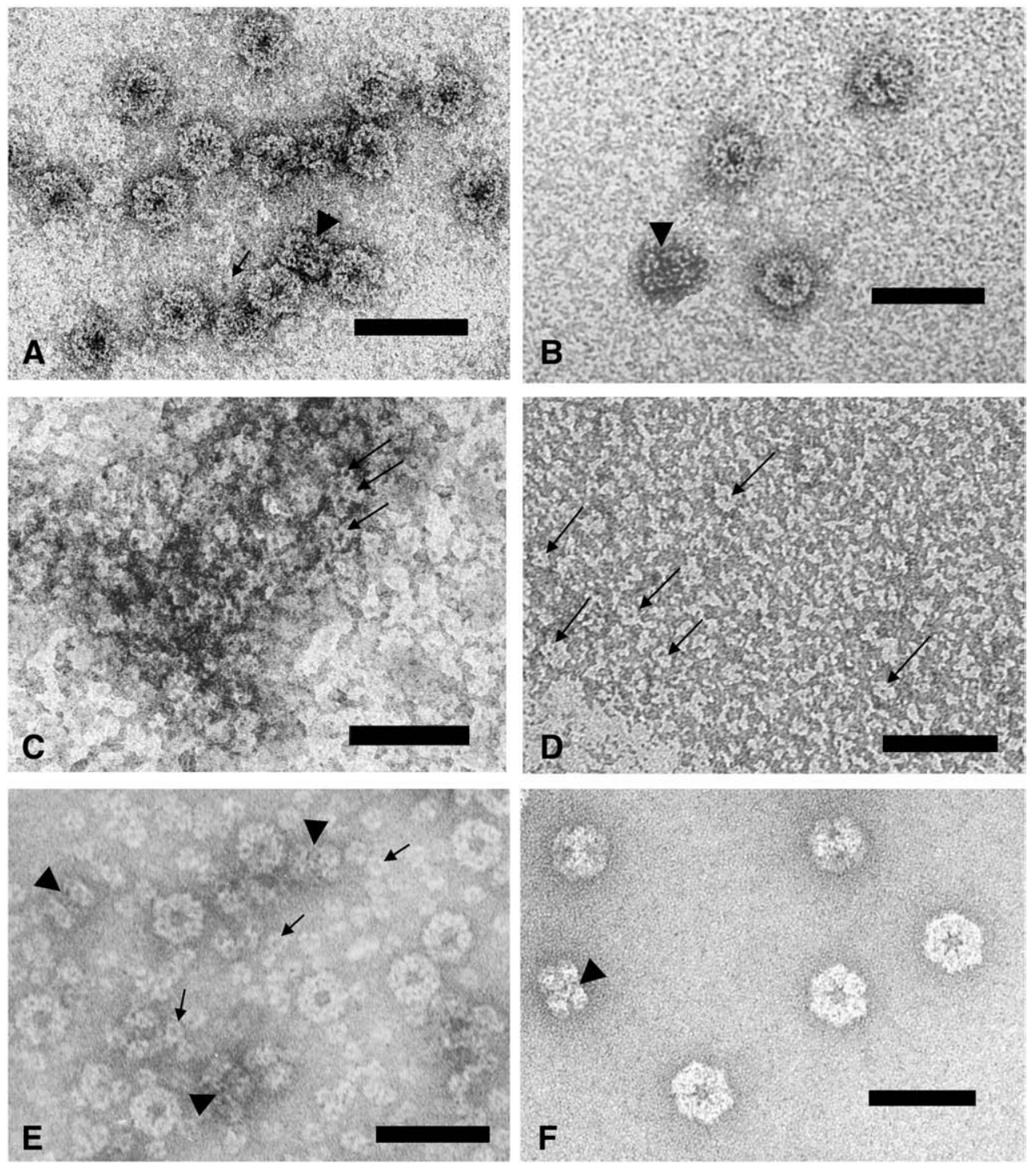

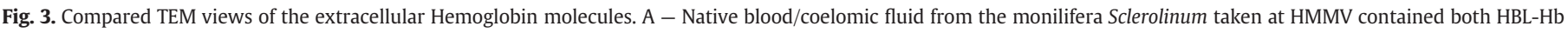

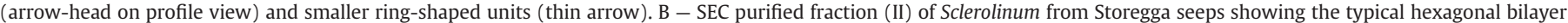

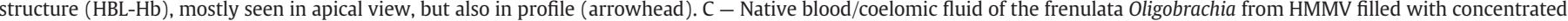

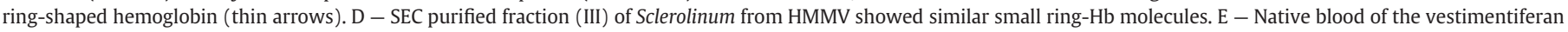

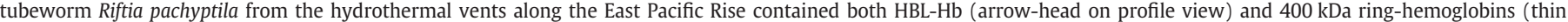
arrows). F - Native blood from the intertidal burrowing lugworm Arenicola marina has HBL-Hb only. Scale bar in each figure is $50 \mathrm{~nm}$.

Conversely to the widespread HBL-Hb, the ring- $\mathrm{Hb}$ is only reported from siboglinids. Within siboglinids, both $\mathrm{HBL}-\mathrm{Hb}$ and ring-Hb are present in vestimentifera and monilifera, whereas frenulata (as least the 8 species investigated so far, from which the genera Diplobrachia, Siboglinida and Oligobrachia.) have the ring-Hb only. Current phylogenetic hypotheses are consensual about the basal positions of the frenulata in the siboglinid tree (Rouse et al., 2004; Halanych 2005). The parsimonious hypothesis would thus imply that frenulata must have lost the ability to synthesize HBL-Hb, due to missing linkers. It would be interesting to check their genome to see, whether frenulata have silent linker genes, or whether the linker genes are lacking. This question could also be addressed for polychetes that do not have HBL, but other types of hemoglobin such as intracellular $\mathrm{Hb}$, to help elucidate the evolutionary history of heme proteins.

\subsection{Hemoglobins mass and size}

Measured with MALLS having a precision of about 5\%, Sclerolinum $\mathrm{HBL}-\mathrm{Hb}$ is $3190 \pm 50 \mathrm{kDa}$, a mass that fits within the range of HBL-Hb masses determined by various techniques (Hanin et al., 2003). It is a slightly smaller mass than the $3500 \mathrm{kDa}$ determined by MALLS for the HBL-Hb in the vestimentifera Riftia pachyptila (Zal et al., 1996b). Measured under TEM, Sclerolinum HBL-Hb has a size of $22.8 \times 16.4 \mathrm{~nm}$ that is not far from those of the vestimentifera Riftia pachyptila $24.5 \times 16 \mathrm{~nm}$ (Terwilliger 1980), and slightly smaller than the non siboglinid polychete Arenicola marina $30.0 \times 19.7 \mathrm{~nm}$ (Toulmond et al., 1990).

Oligobrachia ring- $\mathrm{Hb}$ has a molecular mass of $409 \pm 3.7 \mathrm{kDa}$, and Sclerolinum is $460 \pm 46 \mathrm{kDa}$. These sizes are comparable to those of the 400-kDa hemoglobin evidenced in other pogonophora (Terwilliger et al., 1987; Numoto et al., 2005). The two ring-Hb masses in Riftia are $433 \mathrm{kDa}$ for the vascular V2 and $380 \mathrm{kDa}$ for the coelomic C1 (Zal et al., 1996b). In spite of slightly varying masses from species to species, due to sequence variations in their monomeric components, these hemoglobins show quaternary structures that appear as similar ring-shaped structures, when observed under TEM. However, the crystal structures of the $400 \mathrm{kDa} \mathrm{Hb}$ from Lumbricus, Riftia and Oligobrachia mashikoi clearly show four kinds of globins. They are 


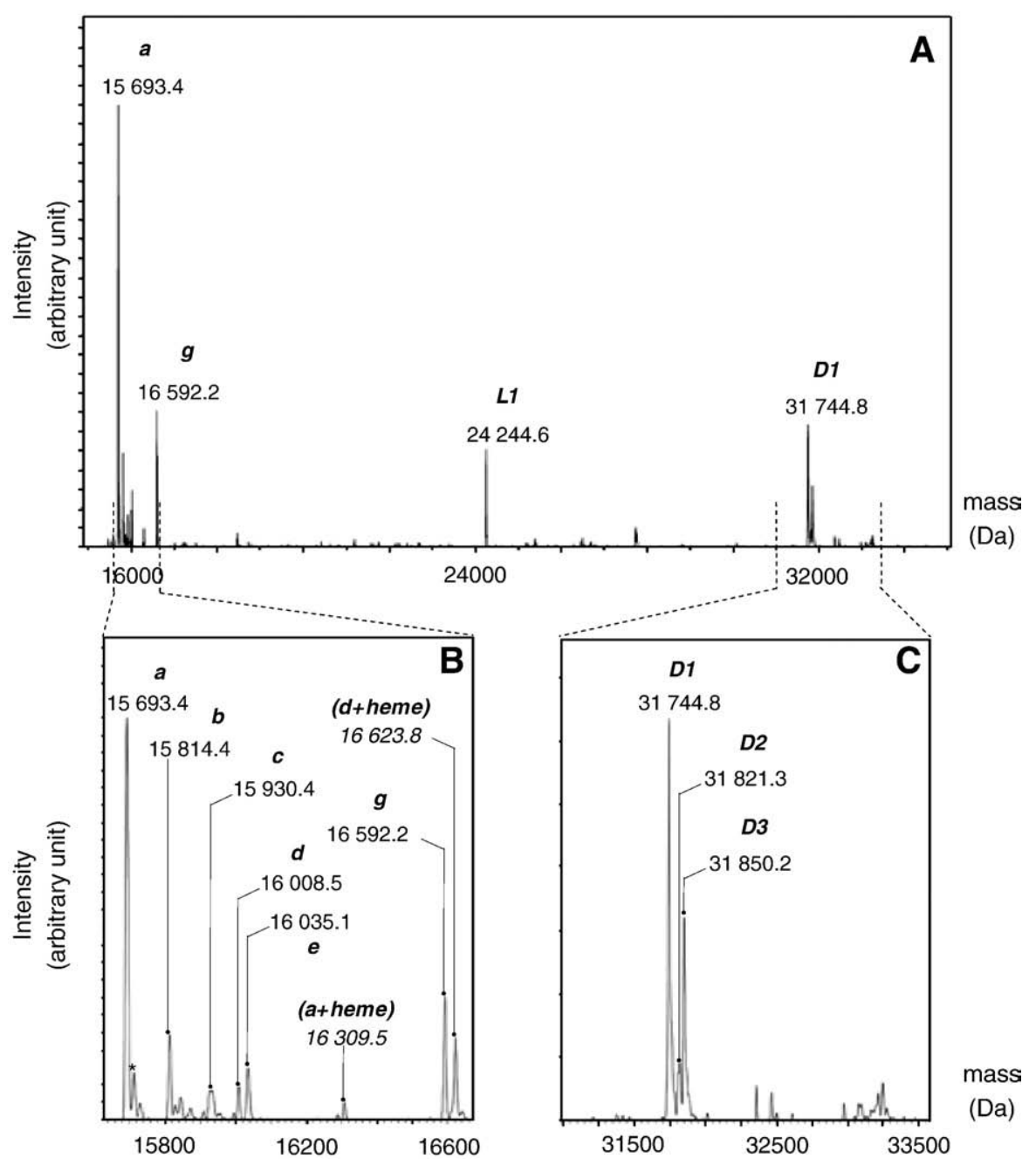

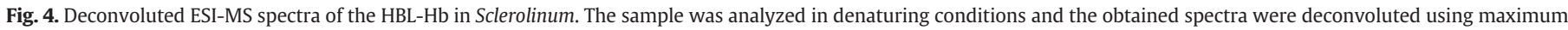

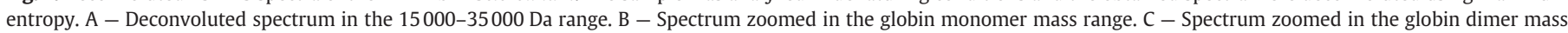

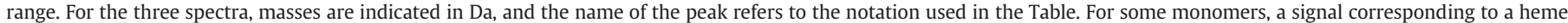
adduct was observed, and is indicated by the letter (h).

associated as disulfide-bonded dimers or trimers that in fact are assembled as a bi-dodecameric globular and hollow-spherical structure (Numoto et al., 2005). This dodecameric assemblage would be the fundamental structural unit of both $400 \mathrm{kDa} \mathrm{Hb}$ and

Table 1

Molecular masses of the hemoglobin components obtained by ESI-MS.

\begin{tabular}{|c|c|c|c|c|}
\hline \multicolumn{2}{|l|}{ Species } & \multicolumn{2}{|c|}{ Sclerolinum contortum } & \multirow{2}{*}{$\begin{array}{l}\text { Oligobrachia webbi } \\
\text { Ring } \mathrm{Hb} \\
\text { (Da) }\end{array}$} \\
\hline Sub-units & Chains & $\begin{array}{l}\text { HBL-Hb } \\
\text { (Da) }\end{array}$ & $\begin{array}{l}\text { Ring-Hb } \\
\text { (Da) }\end{array}$ & \\
\hline \multirow{7}{*}{$\begin{array}{l}\text { Globin } \\
\text { monomers }\end{array}$} & $\mathrm{a}$ & $15693.5 \pm 1.5$ & $15693.6 \pm 1.5$ & $14946.2 \pm 1.5$ \\
\hline & $\mathrm{b}$ & $15814.4 \pm 1.5$ & - & $15054.3 \pm 1.5$ \\
\hline & $\mathrm{c}$ & $15928.7 \pm 1.5$ & $15926.3 \pm 1.5$ & $15066.0 \pm 1.5$ \\
\hline & $\mathrm{d}$ & $16009.6 \pm 1.5$ & $16008.0 \pm 1.5$ & - \\
\hline & e & $16034.8 \pm 1.5$ & $16033.3 \pm 1.5$ & - \\
\hline & f & $16578.9 \pm 1.5$ & $16579.7 \pm 1.5$ & - \\
\hline & $\mathrm{g}$ & $16592.4 \pm 1.5$ & $16592.5 \pm 1.5$ & - \\
\hline \multirow[t]{3}{*}{ Globin Dimers } & $\mathrm{D} 1(\mathrm{~b}+\mathrm{c})$ & $31745.0 \pm 3.0$ & $31745.1 \pm 3.0$ & - \\
\hline & $\mathrm{D} 2(\mathrm{~b}+\mathrm{d})$ & $31820.4 \pm 3.0$ & $31822.9 \pm 3.0$ & - \\
\hline & D3 $(b+e)$ & $31850.3 \pm 3.0$ & $31850.6 \pm 3.0$ & - \\
\hline \multirow[t]{3}{*}{ Linkers } & L1 & $24244.8 \pm 3.0$ & - & - \\
\hline & $\mathrm{L} 2$ & $24280.2 \pm 3.0$ & - & - \\
\hline & L3 & $27733.1 \pm 3.0$ & - & - \\
\hline
\end{tabular}

The nomenclature is that of the mass spectra in denaturing conditions (see Fig. 4).
$3500 \mathrm{kDa} \mathrm{Hb}$ (Numoto et al., 2005). On the other hand, Oligobrachia $400 \mathrm{kDa} \mathrm{Hb}$ in the present study has three kinds of globins, with no disulfide-bonded dimers, nor trimers. It would therefore be very interesting to look at the structure of its crystal to determine whether it is also associated as a bi-dodecamer, or if its structure is somehow different from the other annelids investigated so far.

\subsection{Comparison of hemoglobins molecular structure}

Sclerolinum HBL-Hb is composed of seven monomeric globin chains, two sulfide-bonded globin dimers and three linker-chains. Comparatively Riftia HBL-Hb has only two monomeric globins, a single dimer and four types of linkers (Zal et al., 1996a). Lamellibrachia HBL-Hb has the opposite proportion: four monomeric globin chains and two linkers (Suzuki et al., 1988). None of the globin masses determined here were identical to those recorded for HBL-Hb sub-units in any other annelid, measured with the same method (Bruneaux et al., 2008). The diversity of globins appears much greater in Sclerolinum than in vestimentifera. However part of this diversity could be due to glycosylation of some of them, as shown in Riftia, for which the lightest globin chain (a) has five different glycosylation states (a1-a5) (Zal et al., 1996a). Further deglycosylation experiments can be performed when more samples are available. 
Relative ESIMS intensity

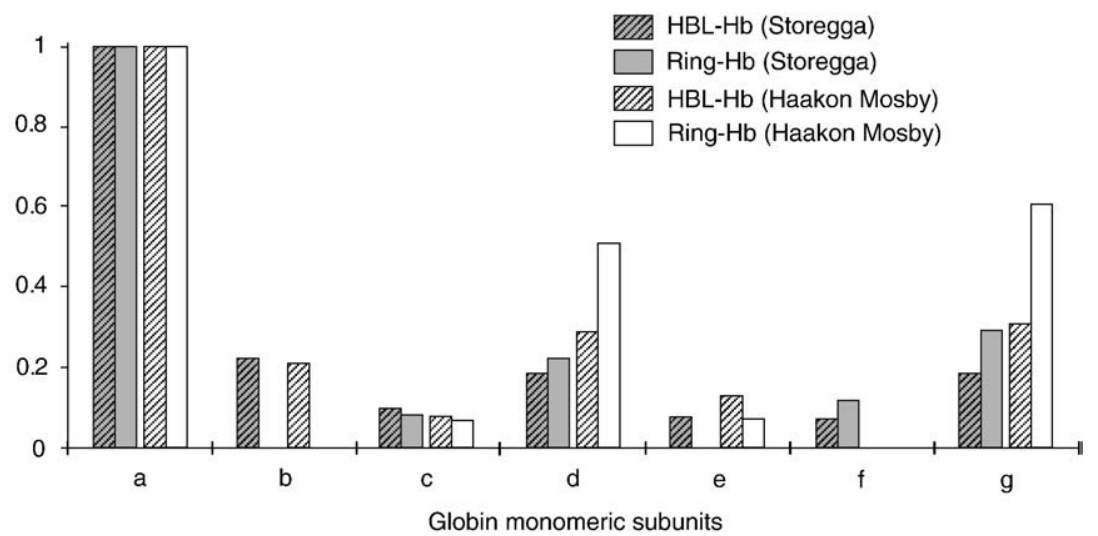

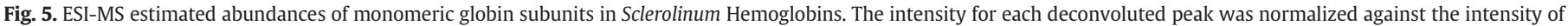
the highest peak of the spectrum. Globins are sorted and named by increasing molecular mass (see Table 1 and Fig. 4).

The presence of globin dimers in Sclerolinum HBL-Hb seems to be a feature that monilifera share with the vestimentifera species analyzed so far. Among annelids, globin dimers are also present in the HBL-Hb of clitellata (except Lumbricus (Martin et al., 1996)), as in the HBL-Hb of the polychete sabellids and in the orbiniid Methanoaricia dendrobranchiata from brine pool seeps. Most of the other polychete families have globin trimers, for review see Bruneaux et al. (2008).

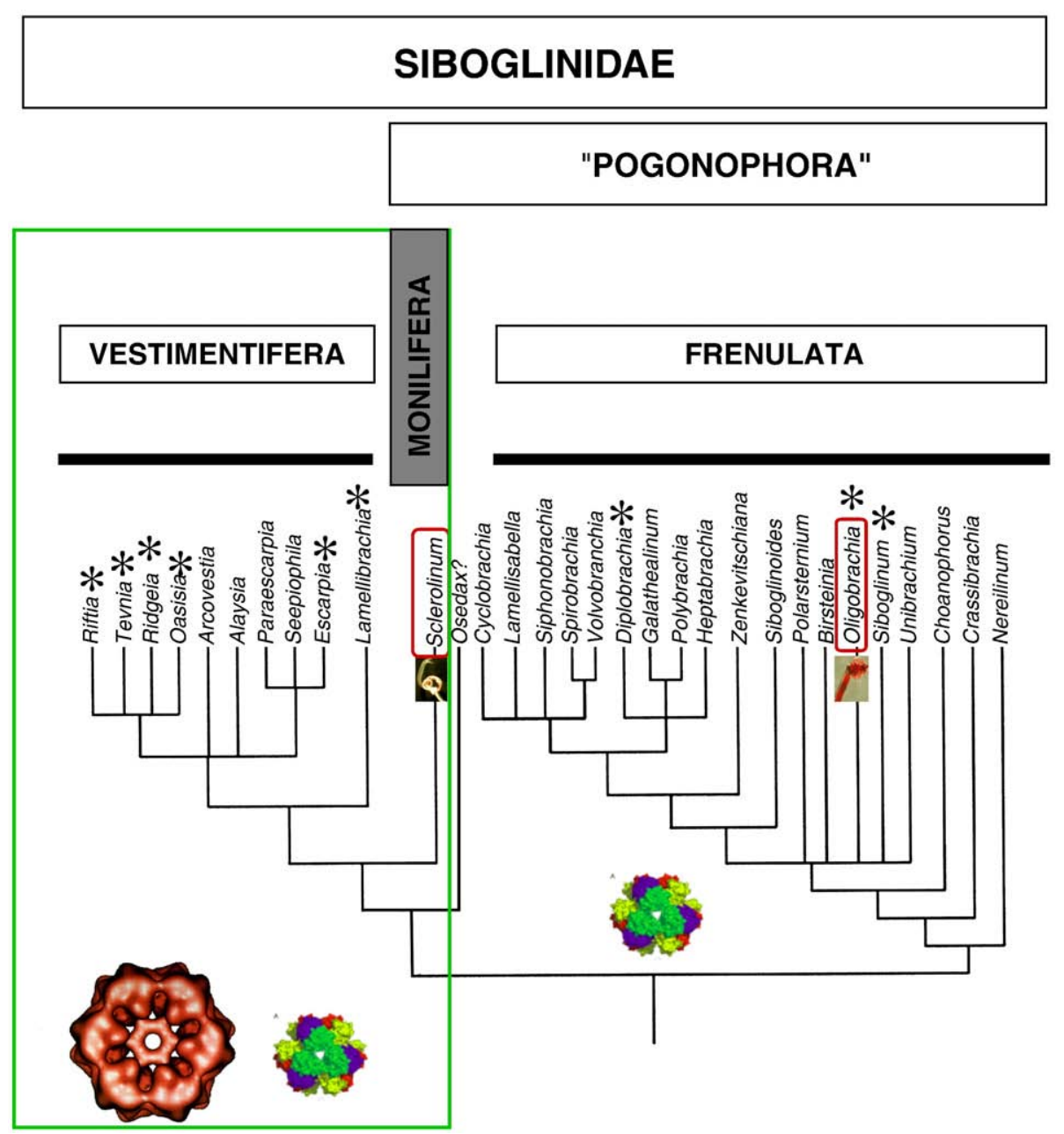

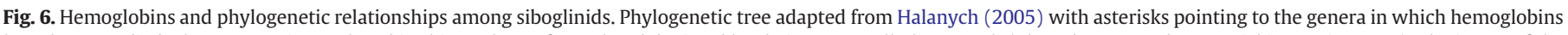

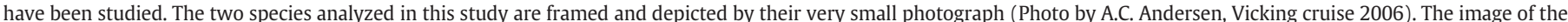

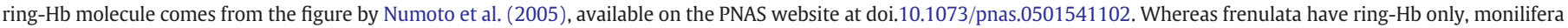

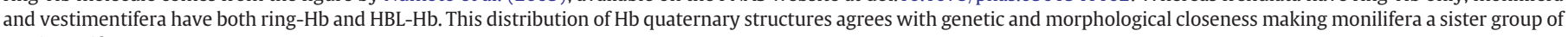
vestimentifera. 
Sclerolinum ring-Hb is composed of the same globin monomers and dimers as the HBL-Hb, except for the chain b present in the dimer only, but not as a free monomer. Thus, the chain b seems to be compulsory for the formation of dimers both in Sclerolinum $\mathrm{HBL}-\mathrm{Hb}$ and in ring-Hb. Concerning ring-Hb, Riftia has two kinds: one in the vascular system (V2) and one in the coelomic fluid (C1). Both have globin chains of very similar molecular masses, although V2 has 6 globins, and C1 only 5, lacking the globin of lightest molecular mass (Zal et al., 1996a). The very small size of Sclerolinum does not enable do dissect the blood system from the coelomic compartments, to determine the precise localization of HBL-Hb and ring-Hb in the body fluids. Riftia vascular ring-Hb also exhibits great globin diversity with six globin chains, from which four are also present in its HBL-Hb (Zal et al., 1996a). This means that the two hemoglobin types differ much more in Riftia than in Sclerolinum, where HBL-Hb and ring-Hb are built by the same globin chains and differ only by the presence of linker chains in the HBL-Hb.

The comparison of relative globin monomers abundances in Sclerolinum hemoglobins between the two collection sites tends to show that globin chain-a of lightest molecular weight is the most represented in both ring-Hb and HBL-Hb from both sites. On the contrary chain-b is lacking as monomer in the ring- $\mathrm{Hb}$ at all sites (but is present in the dimers). Globin chain-f is lacking in the tubeworms' hemoglobins from HMMV, as also chain-e in the ring- $\mathrm{Hb}$ from Storegga. These structural differences in the hemoglobins from Sclerolinum tubeworms collected at either site could reflect genetic differences between distinct populations, which are geographically distant from several hundred kilometers. Local environmental factors may also influence the gene expression and its resulting physiological outcome within unique species, such as shown previously in the two ecotypes of Ridgiea piscesae (Carney et al., 2007). The consequences of the structural differences on the function of the molecule, as to its oxygen affinity are currently under analysis.

\section{Acknowledgments}

We wish to express our thanks to the pilot-team of the ROV Victor 6000 and to the crew of the research vessel "Pourquoi pas?" and last, but not least to Dr. Hervé Nouzé, chief-Scientist during the Vicking cruise, for the collection of the tubeworms. Many thanks to Karine Olu and Philippe Noël for providing blade cores and sieves for the tubeworm extraction. We thank Dr. Claude Jouin-Toulmond for the TEM picture of Riftia pachyptila blood, and Jean Sourimant, technician for the TEM platform for taking the picture of the Arenicola marina blood. This research was supported by the HERMES project, EC contract no GOCE-CT-2005-511234, funded by the European Commission's Sixth Framework Program under the priority 'Sustainable Development, Global Change and Ecosystems'.

\section{References}

Arp, A.J., Childress, J.J., Vetter, R.D., 1987. The sulfide-binding protein in the blood of the vestimentiferan tube worm, Riftia pachyptila, is the extracellular haemoglobin. J. Exp. Biol. 128, 139-158.

Arp, A.J., Doyle, M.L., Di Cera, E., Gill, S.J., 1990. Oxygenation properties of the two cooccuring hemoglobins of the tube worm Riftia pachyptila. Respir. Physiol. 80, 323-334.

Braby, C.E., Rouse, G.W., Johnson, S.B., Jones, W.J., Vrijenhoek, R.C., 2007. Bathymetric and temporal variation among Osedax boneworms and associated megafauna on whale-falls in Monterey Bay, California. Deep Sea Res Part I Oceanogr Res Papers 54, 1773-1791.

Brattegard, T., 1966. A new species of multitentaculate Pogonophora from northern Norway (Oligobrachia webbi). Sarsia 22, 55-63.

Bruneaux, M., Rousselot, M., Leize, E., Lallier, F.H., Zal, F., 2008. The structural analysis of large noncovalent oxygen binding proteins by MALLS and ESI-MS: a review on annelid hexagonal bilayer hemoglobin and crustacean hemocyanin. Curr. Protein Peptide Sci. $9,150-180$.

Carney, S.L., Flores, J.F., Orobona, K.M., Butterfield, D.A., Fisher, C.R., Schaeffer, S.W. 2007. Environmental differences in hemoglobin gene expression in the hydrothermal vent tubeworm, Ridgeia piscesae. Comp. Biochem. Physiol. Part B: Biochem. Mol. Biol. 146, 326-337.

Green, B.N., Gotoh, T., Suzuki, T., Zal, F., Lallier, F.H., Toulmond, A., Vinogradov, S.N. 2001. Observation of large, non-covalent subassemblies in the approximately
$3600 \mathrm{kDa}$ hexagonal bilayer hemoglobins by the electrospray time-of-flight mass spectrometry. J. Mol. Biol. 301, 553-560.

Halanych, K.M., 2001. Molecular evidence that Sclerolinum brattstromi is closely related to Vestimentiferans, not to frenulate pogonophorans. Biol. Bull. 201, 65-75.

Halanych, K.M., 2005. Molecular phylogeny of siboglinid annelids (a.k.a. pogonophorans): a review. Hydrobiologia 535 (536), 297-307.

Hanin, L., Green, B., Zal, F., Vinogradov, S., 2003. Mass distributions of a macromolecular assembly based on electrospray ionization mass spectrometric masses of the constituent subunits. J. Biosci. 28, 557-568.

Ivanov, A.V., 1963. Pogonophora. Pogonophora. Academic Press, London, p. 499

Ivanov, A.V., 1991. Monilifera - a new subclass of Pogonophora. Dokl Akad Nauk, USSR 319, 505-507.

Jones, M.L., 1981. Riftia pachyptila Jones: observations on the vestimentiferan worm from the Galapagos rift. Science 213, 333-336.

Lösekann, T., Robador, A., Niemann, H., Knittel, K., Boetius, A., Dubilier, N., 2008. Endosymbioses between bacteria and deep-sea siboglinid tubeworms from an Arctic Cold Seep (Haakon Mosby Mud Volcano, Barents Sea). Environ. Microbiol. 10 3237-3254.

Martin, P.D., Kuchumov, A.R., Green, B.N., Oliver, R.W.A., Braswell, E.H., Wall, J.S., Vinogradov, S.N., 1996. Mass spectrometric composition and molecular mass of Lumbricus terrestris hemoglobin: a refined model of its quaternary structure. J. Mol. Biol. 255, 154-169.

Nakagawa, T., Onoda, S., Kanemori, M., Sasayama, Y., Fukumori, Y., 2005. Purification, characterization and sequence analyses of the extracellular giant hemoglobin from Oligobrachia mashikoi. Zool. Sci. 22, 283-291.

Numoto, N., Nakagawa, T., Kita, A., Sasayama, Y., Fukumori, Y., Miki, K., 2005. Structure of an extracellular giant hemoglobin of the gutless beard worm Oligobrachia mashikoi. Proc. Natl Acad. Sci. USA 102, 14521-14526.

Numoto, N., Nakagawa, T., Kita, A., Sasayama, Y., Fukumori, Y., Miki, K., 2006. Crystallization and preliminary X-ray crystallographic analysis of extracellular giant hemoglobin from pogonophoran Oligobrachia mashikoi. Biochim. Biophys. Acta 1750, 173-176.

Numoto, N., Nakagawa, T., Kita, A., Sasayama, Y., Fukumori, Y., Miki, K., 2008. Structure of the partially unliganded met state of $400 \mathrm{kDa}$ hemoglobin: Insights into ligandinduced structural changes of giant hemoglobins. Proteins - Struct Funct Bioinformat 73, $113-125$.

Rouse, G.W., 2001. A cladistic analysis of Siboglinidae Caullery, 1914 (Polychaeta Annelida): formerly the phyla Pogonophora and Vestimentifera. Zool. J. Linn. Soc $132,55-88$

Rouse, G.W., Goffredi, S.K., Vrijenhoek, R.C., 2004. Osedax: bone-eating marine worms with dwarf males. Science 305, 668-671.

Schmaljohann, R., Flugel, H.J., 1987. Methane-oxidizing bacteria in pogonophora. Sarsia 72, 91-98.

Southward, E.C., 2000. Class Pogonophora. In: Beesley, P.L., Ross, G.J.B., Glasby, C.J (Eds.), Polychaetes and Allies. The southern synthesis. Fauna of Australia., vol. 4A Polychaeta, Myzostomida, Pogonophora, Echiura, Sipuncula. CSIRO Publishing, Canberra, pp. 331-351.

Southward, A.J., Southward, E.C., 1963. Notes on the biology of some Pogonophora. J. Mar Biol. Assoc. UK 60, 171-174.

Suzuki, T., Takagi, T., Ohta, S., 1988. N-terminal amino acid sequence of the deep-sea tube worm haemoglobin remarkably resembles that of annelid haemoglobin. Biochem. J. $255,541-545$.

Suzuki, T., Takagi, T., Ohta, S., 1993. N-terminal amino acid sequences of $440 \mathrm{kDa}$ hemoglobins of the deep-sea tube worms, Lamellibrachia sp-1, Lamellibrachia sp-2 and slender Vestimentifera Gen Sp-1 evolutionary relationship with annelid hemoglobins. Zool. Sci. 10, 141-146.

Terwilliger, R.C., 1980. Structures of invertebrate hemoglobins. Am. Zool. 20, 53-67.

Terwilliger, R., Terwilliger, N., Bonaventura, C., Bonaventura, J., Schabtach, E., 1985 Structural and functional properties of hemoglobin from the vestimentiferan Pogonophora, Lamellibrachia. Biochim. Biophys. Acta 829, 27-33.

Terwilliger, R.C., Terwilliger, N.B., Hughes, G.M., Southward, A.J., Southward, E.C., 1987 Studies on the haemoglobins of the small pogonophora. J. Mar. Biol. Assoc. UK 67, 219-234.

Toulmond, A., El Idrissi Slitine, F., De Frescheville, J., Jouin, C., 1990. Extracellular hemoglobins of hydrothermal vent annelids: structural and functional characteristics in three alvinellid species. Biol. Bull. 179, 366-373.

Valentine, R.G., Shapiro, B.M., Stadtman, E.R., 1968. Regulation of glutamine synthetase. XII. Electron microscopy of the enzyme from Escherichia coli. Biochemistry 7, 2143-2152.

Yuasa, H.J., Green, B.N., Takagi, T., Suzuki, N., Vinogradov, S.N., Suzuki, T., 1996. Electrospray ionization mass spectrometric composition of the $400 \mathrm{kDa}$ hemoglobin from the pogonophoran Oligobrachia mashikoi and the primary structures of three major globin chains. Biochim Biophys Acta - Protein Struct Mol Enzym 1296, 235-244.

Zal, F., Lallier, F.H., Green, B.N., Vinogradov, S.N., Toulmond, A., 1996a. The multihemoglobin system of the hydrothermal vent tube worm Riftia pachyptila. 2. Complete polypeptide chain composition investigated by maximum entropy analysis of mass spectra. J Biol Chem 271, 8875-8881.

Zal, F., Lallier, F.H., Wall, J.S., Vinogradov, S.N., Toulmond, A., 1996b. The multi-hemoglobin system of the hydrothermal vent tube worm Riftia pachyptila.1. Reexamination of the number and masses of its constituents. J. Biol. Chem. 271, 8869-8874.

Zal, F., Suzuki, T., Kawasaki, Y., Childress, J.J., Lallier, F.H., Toulmond, A., 1997. Primary structure of the common polypeptide chain b from the multi-hemoglobin system of the hydrothermal vent tube worm Riftia pachyptila: an insight on the sulfide binding-site. Protein Struct Funct Genet 29, 562-574.

Zal, F., Leize, E., Lallier, F.H., Toulmond, A., Van Dorsselaer, A., Childress, J.J., 1998. Ssulfohemoglobin and disulfide-exchange: the mechanisms of sulfide-binding by Riftia pachyptila hemoglobins. Proc. Natl Acad. Sci. USA 95, 8997-9002. 